\title{
Economic returns to education: What We Know, What We Don't Know, and Where We Are Going-Some brief pointers ${ }^{\text {is }}$
}

\author{
Matt Dickson ${ }^{\mathrm{a}}$, Colm Harmon ${ }^{\mathrm{b}, *}$ \\ a UCD Geary Institute, University College Dublin, Ireland; CMPO, University of Bristol, United Kingdom; IZA, Bonn, Germany \\ b UCD Geary Institute, University College Dublin, Ireland; Research School of Economics, Australian National University, Australia; IZA, Bonn, Germany
}

\section{A R T I C L E I N F O}

\section{Article history:}

Received 9 August 2011

Accepted 10 August 2011

\section{JEL classification:}

J08

J30

$\mathrm{J} 38$

C21

\section{Keywords:}

Returns to education

Education policy

\begin{abstract}
A B S T R A C T
The estimation of the economic return to education has perhaps been one of the predominant areas of analysis in applied economics for over 50 years. In this short note we consider some of the recent directions taken by the literature, and also some of the blockages faced by both science and policymakers in pushing forward some key issues. This serves by way of introduction to a set of papers for a special issue of the Economics of Education Review.
\end{abstract}

(c) 2011 Elsevier Ltd. All rights reserved.

\section{Introduction}

Economics has invested much energy in identifying the value of educational investment, to determine whether governments and individuals are investing optimally. Much of this work stems from, inter alia, the work of Becker (1962) that introduced the concept of treating investment in education as a capital investment. Since then hundreds of papers have been published estimating the return to education investment (see, for example, the reviews by Card (1999), Harmon, Oosterbeek, and Walker (2003), and the meta analysis of Ashenfelter, Harmon, and Oosterbeek

\footnotetext{
is Our thanks to Cathy Redmond for excellent research assistance - and many discussions - on this brief note, and to colleagues Liam Delaney, Kjell Salvanes, Ian Walker, participants at the Bristol workshop, and the many referees that assisted us in our task of putting this special issue together. The usual disclaimer applies. Dickson acknowledges the support of the EC Framework FP7 programme, grant number PIEF-GA-2010-275964, which facilitated this collaboration.

* Corresponding author. Tel.: +353 17164614; fax: +353 17161108.

E-mail address: colm.harmon@ucd.ie (C. Harmon).
}

(1999) for research on private returns to schooling; de la Fuente and Ciccone (2003) for research addressing the impact of education on the so-called 'knowledge economy' through growth models; and Acemoglu and Angrist (2001) or Oreopoulos and Salvanes (2011) for research on wider externalities associated with education).

However, estimates of this return vary significantly, depending on the data sets used, the assumptions made and the estimation techniques. In terms of broad methodologies, the focus on the issue of endogeneity often requires identifying assumptions that cannot be empirically tested or are, at best, somewhat fragile in estimation. Furthermore, attempts at estimating a single rate of return may not be very informative if returns to education differ by education level, or differ across populations (including by social strata). This may be particularly important for policy responses, but ironically gets masked by methodological debates. Similarly, economists often fail to take into account the risk associated with education investment decisions. Risk may play an important role in an individual's education investment decision, and indeed a government's educational investment level, and should be taken 
into consideration when testing rationality and optimality of education investment (see Heckman, Lochner, and Todd (2008) and the comprehensive review in Heckman, Lochner, and Todd (2006)). In addition, as most cogently argued by Oreopoulos and Salvanes (2011), the return to education may be much wider than the private financial returns that is the focus of so much of the economics literature, and perhaps economics as a profession has allowed a major body of research on the non-pecuniary returns (which may create private returns through externalities that are as great - if not greater - than the direct effect of education on earnings) to become dominated by the other social sciences.

\section{Brief thoughts on current directions}

The papers in this issue are indicative of a trend in the literature to consider (a) a broader concept of monetary private returns to education that considers earnings variance as much as average earnings, and considers variation in returns across the distribution of education; and (b) a wider consideration of non-monetary returns for both the individual and as a means of capturing the likely social returns.

In addressing the first of these issues our sense is that the key requirement is methodological. Even though IV has been used most frequently to causally estimate the returns from education, there has been a debate recently in the literature about the appropriateness of this approach. Heckman and Urzua (2009) outline a number of potential problems associated with IV estimation; weak instruments can give biased estimates; IV estimates rest on strong, $a$ priori data assumptions; in a heterogeneous model, different instruments will give different estimates; and finally, the IV estimate, depending on the instrument used and assumptions made will give different estimates of the return to education, which are often incorrectly interpreted. Advancements have been made recently in this area, with Heckman and Vytlacil (2005) proposing the estimation of marginal treatment effects whereby different treatment effects typically estimated by researchers (local/average treatment effects (L/ATE); treatment on the treated (TT); treatment on the untreated (TUT); policy relevant treatment effect (PRTE); IV and OLS estimates) can all be estimated from different weighted averages of the marginal treatment effect. Other research has developed the traditional two choice model to ordered choice models and to general unordered choice models which allow heterogeneity of response to treatments (Heckman and Vytlacil, 2005; Heckman, Tobias, \& Vytlacil, 2001).

of a similar nature, if the simplest, so-called Mincer, coefficient is assumed to be the rate of return that individuals consider when deciding their educational attainment levels, then returns to education must be risk free or the individual is risk neutral. However, returns to education are not risk free, and, typically, individuals are not risk neutral. Therefore, the risk associated with different educational attainment levels and the degree of individual risk aversion will impact upon educational attainment choices. Harmon, Hogan, and Walker (2003), using UK Labour Force Survey data from 1993 to 2000, estimated that mean returns to education of 7 percent are associated with a 4 percent standard deviation. Borrowing directly from the finance literature, Palacios-Huerta (2003) computes the Sharpe ratio of human capital investments for different demographic groups and education levels (the Sharpe ratio of an investment is the ratio of the expected returns to the standard deviation of returns), and compares this to the Sharpe ratio available in financial markets-for many demographic groups and education levels the human capital Sharpe ratio was greater than that available in financial markets. Melnik, Pollatschek, and Comay (1973) and Heckman, Lochner, and Todd (2008) consider the option value associated with an additional year of education. This option value arises for two different reasons. One is due to the non-linearity of returns to different years of education-an additional year of education confers the option to go on to further levels of education that might be associated with higher returns. However, an additional year of education also gives you more information about labour market returns and your own ability. This additional information reduces the uncertainty of returns to future levels of education, and might enable you to make better-informed decisions about your educational attainment levels, resulting in better outcomes.

With respect to the estimation of wider returns, the basic Mincer model does not allow for non-monetary returns. If non-monetary returns to education exist, then the Mincer estimate will underestimate the public/private returns from education. Many papers have been published linking education and non-market benefits. Haveman and Wolfe (1984) outline many private non-monetary benefits including own health, spouse and family health, fertility (achieving desired family size and changing of family size preferences), broadened enjoyment of other activities, consumer choice efficiency, higher saving rates and improved marital sorting. They also review public non-monetary benefits including crime reduction, social cohesion, technological change and charitable giving. There have been a number of more recent papers investigating the causal impact of education on non-monetary outcomes. For example, Lochner (2004) finds that education reduces criminal behaviour, and the social value of this return equates to between 14 and 26 percent of the private return to schooling. Milligan, Moretti, and Oreopoulos (2004) find that education increases voter turnout in the United States (but not in the United Kingdom). They also find that education leads to more politically informed citizens. Similarly, Dee (2004) finds that education increases voter turnout, free speech and civic knowledge. Oreopoulos (2007) finds that in addition to increasing lifetime wealth by approximately 15 percent, an additional year of schooling reduces the likelihood of being in poor health, being unemployed and being unhappy.

\section{This issue-brief outline of the papers}

Many of the topics outlined in Section 2 were the motivation of a symposium held at the University of Bristol's Centre for Market and Public Organisation (CMPO) in 
September $2010,{ }^{1}$ which forms the basis of this special issue of the Economics of Education Review which discusses the various issues motivating current directions in the returns literature and introduces a selection of papers inspired by the symposium. In putting this issue together we hoped to both consider current approaches to estimating economic returns to education, as well as broadening the concept of returns.

One suite of papers use educational reform as instruments to deal with endogeneity in common with a wider literature, although in doing so they take a different angle on the problems through, for example, a focus on particular aspects of the educational distribution. In their paper, Devereux and Fan (2011) fit into the tradition of studies based on IV to uncover the causal effects of education on earnings. Based on UK data, the paper studies the effects of a major expansion in education levels that occurred for persons born between 1970 and 1975 where, following a long period of stagnation in educational levels, the average age of finishing education increased by about one year over the space of these cohorts. While this period has been considered one of higher educational expansion, the authors demonstrate that large increases in educational attainment occurred throughout the educational distribution, with a higher proportion of persons staying in school beyond age 16 and obtaining high school completion qualifications. The authors show that hourly wages and weekly earnings also increased over this expansion period, and did so in a way that is highly correlated with the educational increases. This suggests that people born late enough to be able to take advantage of the educational expansion also benefited from higher wages as a result of the increased education. When the authors use the educational expansion to estimate the return to education by instrumental variables, they find that the return to an extra year of education is about $6 \%$ for both men and women. The findings suggest that, consistent with human capital models, policy-induced increases in educational attainment are of benefit to affected cohorts.

The paper by Walker and Zhu (2011) also focuses on the private returns to education but specifically on the period spent in higher education. They examine the impact of a rise in student fees on the internal rate of return to English undergraduate degrees. Since repayments occur in the future and depend on earnings it is important to get good estimates of the lifecycle pattern of wages. They exploit the short panel nature of their data to obtain estimates of the lifecycle that are (under certain conditions) uncontaminated by cohort effects. They also recognize that the lifecycle pattern of wages differs by college major so estimate separate equations by major. They use these

\footnotetext{
1 http://www.bristol.ac.uk/cmpo/publications/bulletin/winter10/index .html gives a broad introduction to the activity of the symposium including a podcast discussing the issues. The papers in this special issue were taken from the Bristol symposium where the authors were willing to submit. The Editors also invited a number of additional submissions from authors with an interest in this field. Papers were reviewed in the normal manner for the journal, with recommendations of the Issue editors forwarded for final approval to the Managing Editor. Papers that involved either guest editor were, of course, dealt with by the Managing Editor.
}

estimates to simulate the impact of changes in the level of fees (which are set to treble in England) and the structure of the student loan scheme. They also take account of income tax and social security contributions. They find large internal rates of return to some subjects (like economics) and low to others (like arts). Their simulations suggest that even the dramatic increases in fees proposed by the UK Government beginning with the 2011 intake will have only small effects on rates of return.

The contribution by Chevalier (2011), who investigates heterogeneity in a recent cohort of UK graduates, makes an important extension of the Walker and Zhu (2011) paper. Even after controlling for a large array of individual and institution characteristics, large wage differentials are observed. The range between subjects reaches $0.26 \mathrm{log}$ points even after excluding medical degree graduates who are clear outliers. Gender differences of the same order are found for some subjects, even if overall, the gender wage gap is small at three percent. However, these differences in mean wage between subjects are dwarfed by larger differences within subjects. In the view of the current debate on the 'marketisation' of higher education, Chevalier computes a graduate tax to approximate a willingness to pay for these wage differentials. Assuming perfect forecast, he concludes that tuition fees could range from $£ 1900$ to $£ 5300$ by subject, which is considerably less than the planned tuition charge at most institutions of $£ 9000$.

A second set of papers widens the concept of returns to education. Dickson and Smith (2011) explore the return to education in terms of employment outcomes as well as log wages. Moreover, they consider whether instrumental variables estimates of the return, which exploit changes in minimum school leaving ages, may conflate the effect of additional schooling and that of qualifications attainment. After exploiting an institutional feature of the English education system to estimate the effect of attaining qualifications on outcomes, this IV estimate is compared with an IV estimate based on a change in compulsory schooling-which will capture both the impact of additional schooling and of being more likely to attain qualifications. The evidence suggests that being induced to attain some academic qualifications rather than leaving school without any drives much of the estimated return to education derived using IV methods exploiting the 1973 raising of the school leaving age.

Delaney et al. (2011) consider how education, specifically higher education, can address issues such as a social gradient in educational attainment as well as considering the impact of education on career and wage expectations. Their paper uses a particularly rich and innovative dataset of Irish university students that includes a myriad of controls of a psychological nature, which in effect allow for a control of issues such as time preferences. The paper shows how an observed gap in educational attainment by social class at the time of entry to university is all but eliminated by the graduation, but there persists a large and significant gap in the expectations of students whereby poorer students have lower wage expectations. The implication of this is important-if the minority of poorer background students who actually make it to University have such different expectations of earning when objectively they are as 
talented as their richer peers, the gaps in earnings expectations for those more marginally attached to education must be very much larger. In the context of a Mincer style model where participation is largely determined by potential earning returns, this is a critical issue.

Similarly the education systems may also provide alternative incentives for student performance. The work of Clark (2011) considers how policies that fall under the school accountability umbrella are designed to incentivize students-these include high school exit exams that are standardized tests which, in some US states, students must pass to earn a high school diploma. They consider whether these tests induce students to work harder and, therefore, improve their high school performance, or whether these exams prevent some students from graduating and cause others to dropout. In this paper they specifically investigate the impacts of an increase in the exit exam standard in Florida. Using difference-in-difference methods, they show that this had few of the negative effects claimed by critics. While the authors cannot detect any positive effects of the higher standard, such effects may be too small to be picked up with their data.

In terms of broad themes, the remaining papers take a different approach to estimating the return to education, modifying the standard Mincerian approach. Henderson, Solomon and Wang (2011) relax the assumption of homogeneous rates of return to schooling by employing nonparametric kernel regression. This approach allows the examination of the differences in rates of return to education both across and within groups. They find that, on average, blacks have higher returns to education than whites, natives have higher returns than immigrants and younger workers have higher returns than older workers. Contrary to previous studies however they find that the average gap in the rate of return between white and black workers is larger than previously thought and the gap is smaller between immigrants and natives. There is also significant heterogeneity, the extent of which differs both across and within groups. The authors uncover the characteristics common amongst those with the smallest and largest returns to education. Finally, the contribution by Park (2011) explores nonlinearity in the rate of return to education, exploiting respondents in the National Longitudinal Survey of Youth (NLSY) who change jobs with an intervening period of education reinvestment. The conventional assumption of linearity of log wages in years of schooling is strongly rejected: a typical reinvestment for the 1980 through 1993 period is associated with a rise of about 3.5 percentage points in the estimated return to an additional year of schooling. The estimated marginal rate of return generally rises in the former education level, and reaches the maximum where an additional year of investment is associated with a rise in real hourly rate of pay by approximately 20 percent. Park shows that neither sheepskin effects nor sample selectivity is responsible for the finding, nor concurrent technological change.

\section{Conclusion and implications}

Oreopoulos and Salvanes (2011) put the key issues very well - while increasing income and wealth is a key motivator for educational choice, it is arguable whether it is THE motivator. Economics has perhaps been somewhat 'underpowered' in terms of research that recognises how education can define major life outcomes - occupation, marriage/relationships and so on - but also can change you as a person - increasing your sense of self esteem, self awareness and consideration of the future. It changes key skills that are not often captured in standard models education may make you more opinionated, more decisive. It may promote trust, civic engagement. You may also have the skills to avoid lifetime 'traps' - making you better at running your household budget, managing your time and your allocation of time to the benefit of others such as your children.

Some final observations flow from these developments. Firstly, perhaps greater dialogue and understanding between the policy community and the research community would lead to mutually beneficial outcomes? Some things are clear - the focus of economics on causal outcomes is vital and a necessary condition. However, estimating the economic return to schooling has been very focused on the estimation of a point estimate - and moreover, on explaining what the point estimate means through, for example, the IV/LATE literature. We may be throwing the proverbial baby out with the bathwater by ignoring what we as scientists might see as irrelevant. For example, a LATE effect may be a very important effect - indeed, as fiscal positions of governments become ever tighter, the era of universality of policy design may also be over and targeted action (at the 'local' population) will mean that LATE estimates could be critical. Key things discussed in this short note - and this special issue - are all highly policy relevant such as the examination of specific parts of the education/wage distribution, returns to specific qualifications, the motivations of high-and-low achieving children. Understanding wage expectations is perhaps as critical as understanding actual distributions of outcome. Finally, the conventional policy response - throw money at the issue - has been largely unsuccessful in addressing important and persistent policy blockages like low intergenerational educational attainment, suggesting that a more nuanced understanding of the economic returns that include wider external benefits could be vital.

Secondly, the developments of methodological and theoretical underpinnings (such as the increased role of non-cognitive skills in a formal model of human capital skill formation in the work of Heckman and others, or the increasing role of risk in modelling educational choices and outcomes) have important policy implications that need to be thought through in more detail. For example, the presence of risk in education returns provides an interesting alternative justification for government intervention in education markets. If individuals are choosing socially sub-optimal levels of education due to high levels of risk aversion, then the government, by initially subsidising the individual cost of education, and claiming it back through future progressive labour market taxation, could increase a society's educational attainment levels by diversifying individual risk of education investment. In general, the emergence of this literature, that both widens the concept 
of the return as well as the ways of estimating it, can widen the policy choice set substantively and more research will be needed to map that set.

Finally, all of the above can only be turned into empirical application with the right data sources and three main data challenges remain. We need to progress further the linkages between administrative and survey sources, and national agencies need to do this as a matter of course. We need to use social experiments in education more substantively, ideally against a backdrop of the administrative data linkages. Finally, the embedding of measures from the other human sciences (like psychology) can be incredibly powerful in adding to our understanding of matters, but add little in terms of burden or cost to the data collection processes. Many of the papers in this special issue show the value of these data innovations.

We think this is an exciting challenge being posed to the labour/education economics community, and we hope that this special issue goes some way towards starting some of the intellectual debates.

\section{References}

Acemoglu, D. \& Angrist, J. D. (2001). How large are human-capital externalities? Evidence from compulsory-schooling laws. In B. Bernanke, \& K. Rogoff (Eds.), NBER macroeconomics annual (pp. 9-59). Cambridge: National Bureau of Economic Research.

Ashenfelter, O., Harmon, C. \& Oosterbeek, H. (1999). A review of estimates of the schooling/earnings relationship, with tests for publication bias. Labour Economics, 6(3), 453-470.

Becker, G. S. (1962). Investment in human capital: A theoretical analysis. The Journal of Political Economy, 70(5), 9-49.

Card, D. (1999). The causal effect of education on earnings. In O. Ashenfelter, \& D. Card (Eds.), Handbook of labor economics. Rotterdam: Elsevier.

Chevalier, A. (2011). Subject choice and earning of UK graduates. Economics of Education Review, 30(6), 1187-1201.

Clark, D. (2011). The impact of tougher education standards: Evidence from Florida. Economics of Education Review, 30(6), 1123-1135.

Dee, T. S. (2004). Are there civic returns to education? Journal of Public Economics, 88(9-10), 1697-1720.

de la Fuente, A. \& Ciccone, A. (2003). Human capital in a global and knowledge-based economy. European Commission: DG Employment and Social Affairs.
Delaney, L., Harmon, C. \& Redmond, C. (2011). Parental Education, Grade Attainment and Earnings Expectations: Evidence from University Students. Economics of Education Review, 30(6), 1136-1152.

Devereux, P. \& Fan, W. (2011). Earnings returns to the British education expansion. Economics of Education Review, 30(6), 1153-1166.

Dickson, M. R. \& Smith, S. (2011). What determines the return to education: An extra year or a hurdle cleared? Economics of Education Review, 30(6), 1167-1176.

Harmon, C. P., Oosterbeek, H. \& Walker, I. (2003). The returns to education: Microeconomics. Journal of Economic Surveys, 17(2), 115-155.

Harmon, C. P., Hogan, V. \& Walker, I. (2003). Dispersion in the economic return to schooling. Labour Economics, 10(2), 205-214.

Haveman, R. H. \& Wolfe, B. L. (1984). Schooling and economic well-being: The role of nonmarket effects. Journal of Human Resources, 19(3), 377-407.

Heckman, J. J., Lochner, L. \& Todd, P. (2006). Earnings functions, rates of return and treatment effects: The mincer equation and beyond. In $\mathrm{E}$. Hanushek, \& F. Welch (Eds.), Handbook of the economics of education (pp. 307-458). Rotterdam: Elsevier.

Heckman, J. J., Lochner, L. \& Todd, P. (2008). Earnings functions and rates of return. Journal of Human Capital, 2(1), 1-31.

Heckman, J. J., Tobias, J. \& Vytlacil, E. (2001). Four parameters of interest in the evaluation of social programs. Southern Economic Journal, 68(2), 419-442.

Heckman, J. J., \& Urzua, S. (2009). Comparing IV with structural models: What simple IV can and cannot identify. National Bureau of Economic Research Working Paper 14706.

Heckman, J. J. \& Vytlacil, E. (2005). Structural equations, treatment effects and econometric policy evaluation. Econometrica, 73(3), 669-738.

Henderson, D. J., Solomon, J. P. \& Wang, L. (2011). Heterogeneity in schooling rates of return. Economics of Education Review, 30(6), 1202-1214

Lochner, L. (2004). Education, work, and crime: A human capital approach. International Economic Review, 45(3), 811-843.

Melnik, A., Pollatschek, M. A. \& Comay, Y. (1973). The option value of education and the optimal path for investment in human capital. International Economic Review, 14(2), 421-435.

Milligan, K., Moretti, E. \& Oreopoulos, P. (2004). Does education improve citizenship? Evidence from the United States and the United Kingdom. Journal of Public Economics, 88(9), 1667-1695.

Oreopoulos, P. (2007). Do dropouts drop out too soon? Wealth, health and happiness from compulsory schooling.Journal of Public Economics, 91(11-12), 2213-2229.

Oreopoulos, P. \& Salvanes, K. G. (2011). Priceless: The nonpecuniary benefits of schooling. Journal of Economic Perspectives, 25(1), 159-184.

Palacios-Huerta, I. (2003). An empirical analysis of the risk properties of human capital returns. American Economic Review, 93(3), 948-964.

Park, S. (2011). Returning to School for Higher Returns. Economics of Education Review, 30(6), 1215-1228.

Walker, I. \& Zhu, Y. (2011). Differences by degree: Evidence of the net financial rates of return to undergraduates. Economics of Education Review, 30(6), 1177-1186. 